\title{
Narrativa transmedia en el spot publicitario. estudio de caso de las campañas de la lotería de Navidad
}

\author{
Dra. Noelia García-Estévez | noeliagarcia@us.es \\ Universidad de Sevilla
}

\author{
Palabras clave \\ Publicidad; Spot; Transmedia; Storytelling; \\ Narrativa; Digital \\ Sumario \\ 1. Introducción, 2. Metodología, 3. \\ Resultados, 4. Discusión y conclusiones, 5. \\ Bibliografía
}

\section{Resumen}

La narrativa audiovisual publicitaria se ha transformado en los últimos años incorporando en su estructura diferentes dimensiones del entorno digital. Se trata de una nueva forma de construir relatos acorde con las exigencias de los nuevos usuarios, prosumidores capaces de generar, difundir, producir y reproducir contenidos. La narrativa transmedia y el storytelling se integran en campañas $360^{\circ}$ donde no se trata de una única historia, sino de varias interconectadas entre sí, posibilitando que se extienda, se expanda y se enriquezca con otros soportes y canales.

El objetivo de este trabajo es analizar la narrativa audiovisual de la publicidad televisiva en su adaptación al contexto digital transmediático. Tomaremos como estudio de caso las campañas de Lotería de Navidad, realizando una aproximación a su evolución desde el año 1998 a la actualidad. Detenemos nuestra atención en las últimas tres campañas, desde el 2014 al 2016, donde la historia ha ido adquiriendo un papel fundamental. Observamos un verdadero storytelling con el cual Loterías y Apuestas del Estado ha sido capaz de conectar con sus audiencias apelando a su lado emocional. Esta narrativa es, también, transmedia e interactiva, articulada de manera multiplataforma y con la posibilidad de interacción por parte del espectador.

\section{Cómo citar este texto:}

Noelia García-Estévez (2018) Narrativa transmedia en el spot publicitario. estudio de caso de las campañas de la lotería de Navidad. Miguel Hernández Communication Journal, 9 (1), pp. 49 a 70. Universidad Miguel Hernández, UMH (Elche-Alicante). DOI: http://dx.doi.org/10.21134/mhcj.v0i9.229 


\title{
Transmedia narrative in the advertising spot. Case study of the Christmas lottery campaigns
}

\author{
Dra. Noelia García-Estévez | noeliagarcia@us.es \\ Universidad de Sevilla
}

Keywords

Advertising; Spot; Transmedia; Storytelling; Narrative; Digital.

\section{Summary}

1. Introduction, 2. Methodology, 3. Results, 4. Discussion and conclusions, 5. Bibliography

\section{Abstract}

The advertising audiovisual narrative has been transformed in the last years incorporating in its structure different dimensions of the digital context. It is a new way of building stories in line with the demands of new users, prosumers that are able of generating, disseminating, producing and reproducing content. The transmedia narrative and the storytelling are integrated in campaigns $360^{\circ}$ where it is not a single story, but several interconnected ones, making it possible to spread, expand and enrich with other supports and channels.

The objective of this work is to analyze the audiovisual narrative of television advertising in its adaptation to the digital context. We will take as a case study the Christmas Lottery campaigns, making an approximation to its evolution from the year 1998 to the present. We have stopped our attention in the last three campaigns, from 2014 to 2016, where history has been acquiring a fundamental role. We observe a true storytelling with which Loterías y Apuestas del Estado has been able to connect with its audiences by appealing to its emotional side. This narrative is also transmedia and interactive, articulated in a multiplatform way and with the possibility of interaction on the part of the spectator.

How to cite this text:

Noelia García-Estévez (2018) Transmedia narrative in the advertising spot. Case study of the Christmas lottery campaigns. Miguel Hernández Communication Journal, 9 (1), pp. 49 to 70. Universidad Miguel Hernández, UMH (Elche-Alicante). DOI: http://dx.doi.org/10.21134/mhcj.v0i9.229 


\section{Introducción}

Los neurocientíficos y psicólogos analizan como parte de su disciplina por qué a los seres humanos nos gusta contar y escuchar historias, sin importar la edad, el sexo o clase social. Las historias influyen en nuestras emociones y reviven momentos del pasado, generando una identificación y conexión que nos vincula con el relato narrado. Desde la Antigüedad el hombre ha contado leyendas, fábulas e historias que se han ido transmitiendo de generación en generación, manteniendo la memoria de los acontecimientos (Mandler y Johnson, 1977).

La forma de contar y escuchar historias se ha visto, ineludiblemente, alterada por la evolución tecnológica y las características de la propia sociedad. Las formas han cambiado pero lo que se mantiene inalterable es el hecho en sí. "Quizás nada sea más humano que el acto de compartir historias, ya sea ante una hoguera o a través de una «nube», por así decirlo", reconocen Jenkins, Ford y Green (2015: 27). Todo ello marcado por la evolución de las tecnologías de la información y la comunicación avanzando hacia una sociedad de la ubicuidad (Nakamura, 2004 citado en Islas, 2013) y una modernidad líquida (Bauman, 2016). La irrupción y popularización de la web social ha difuminado las artificiosas fronteras entre hipotéticos mundos analógicos y digitales, colocando a marcas y clientes ante un nuevo escenario híbrido en el que contar historias y participar.

Este artículo tiene como objetivo estudiar cómo la narrativa transmedia no solo se ha integrado en los relatos de entretenimiento (programas, películas o series) y de información (informativos o debates) sino que también se ha incorporado en el ámbito de la publicidad y el marketing. Desde la incorporación del concepto transmedia por parte de Jenkins (2003) encontramos numerosas iniciativas tanto informativas, documentales, de entretenimiento y marketing que pretenden ofrecer esta estrategia.

\subsection{Una aproximación a la narrativa transmedia y al nuevo usuario}

La relación marca-cliente ha evolucionado consecuencia, en parte, de las propias exigencias del nuevo consumidor que no se conforma con un rol pasivo y dirigido sino que quiere participar y hacer del proceso de comunicación con la marca una auténtica experiencia. Nos hallamos ante una nueva dimensión donde el engagement es, en efecto, un verdadero compromiso hacia la sinceridad, honestidad, coherencia y emoción. Para conseguir este 
fuerte vínculo las marcas empiezan a contar historias con las que emocionar, crear un storytelling que cuente algo, que aporte y que se comparta, situando al usuario en el centro de la estrategia (Lamelo, 2016: 92).

La narrativa transmedia, por su parte, es una forma de contar historias que implica a los espectadores y se desarrolla en varias plataformas y soportes. Una narrativa transmedia debe cumplir una serie de criterios (Jenkins, 2003, 2006, 2009): la historia se cuenta través de varios medios que amplían el mundo narrativo (no es igual que una adaptación ni coincide exactamente con un crossmedia); la expansión gestionada desde arriba (top-down) por los productores y desde abajo (botton-up) por los usuarios (contenido generado por los usuarios, GCU); el usuario decide su nivel de inmersión y de experiencia con respecto al relato; y la capacidad del mundo narrativo de ser abordado a través de cualquiera de las unidades del relato que lo componen.

En las relaciones mediáticas tradicionalmente se hablaba de audiencias, consumidores o receptores. Ahora los consumidores luchan por el derecho a participar en su cultura (Jenkins, 2008: 28) y todos esos conceptos resultan insuficientes. Necesitamos hablar de usuarios activos y participativos que no se conforman con consumir, convirtiéndose en prosumidores con un papel clave en el panorama mediático actual. Generadores de productos multimedia que responden a intereses económicos, a la vez que enriquecen las historias contadas y la experiencia de los públicos (Belsunces, 2011).

Dentro de esta nueva generación de consumidores, afirma Scolari, hay un sector que quiere ir más allá y convertirse en prosumidores mediáticos capaces de apropiarse de un mundo narrativo y extenderlo. De hecho, afirma el mismo autor, "lo que el productor no quiere, no sabe o no puede producir, lo hará el prosumidor" (2013: 79). Existen diferentes tipologías textuales de contenido generado por el usuario (Scolari, 2013) que van desde la realización de sincronizaciones (reconstrucción a modo de resumen), recapitulaciones (resúmenes de capítulos o temporadas), parodias (creación en forma de comedia), finales alternativos, falsos avances y openings (también llamados re-cut trailers), mashups, remix o cross-overs (que vinculan dos o más mundos narrativos) y adaptaciones (utilizando otra estética o lenguaje). No podemos dejar de hacer aquí referencia al conocido como fenómeno del fandom que, aunque sus orígenes son muy anteriores a la web y la digitalización, se encuentra hoy día en una época dorada sobresaliendo el protagonismo de estas comunidades de apasionados a una serie, película u otro contenido generando además contenidos propios como fanvid, fanfiction, fanart o fansub.

\section{Metodología}

El principal objetivo de esta investigación es analizar las posibilidades del 
transmedia storytelling en el relato audiovisual publicitario. Estudiar cómo la narrativa transmedia no solo se ha integrado en los relatos de entretenimiento (programas, películas o series) y de información (informativos, documentales o debates) sino que también se ha incorporado en el ámbito de la publicidad y el marketing.

Tomamos como estudio de caso el clásico y esperado anuncio de la Lotería de Navidad en España. Más allá del calendario de Adviento, la emisión de este spot en televisión marca de manera significativa para todos los españoles el comienzo 'real' de la Navidad. En su sitio web Loterías y Apuestas del Estado, legalmente Sociedad Estatal Loterías y Apuestas del Estado, S.A., afirma ser el operador de juego más sólido del presente y con más proyección de futuro. Los orígenes de esta lotería se remontan al reinado de Carlos III, cuando el 30 de septiembre de 1763, inspirándose en una tradición procedente de Nápoles, instauró la "Lotería Real" con un formato similar a la actual La Primitiva.

Fue en 1818 cuando se organiza un sorteo especial coincidiendo con la Navidad. Puede considerarse como el origen del Sorteo Extraordinario de Navidad. Aunque no sería hasta 1839 cuando el popular sorteo navideño comienza a celebrarse regularmente; y habría que esperar hasta 1897 para que el sorteo de Navidad recibiera oficialmente dicho nombre. En cuanto a su proyección publicitaria, podemos decir que es a partir del año 1998 cuando el spot que anuncia el Gordo de Navidad adquiere una gran popularidad y se convierte en el inicio de la temporada navideña.

Nos centramos en el estudio de los spots publicitarios de la Lotería de Navidad en España, realizando una aproximación a su evolución desde el año 1998 a la actualidad. Adoptamos el estudio de caso conformando "una investigación empírica que estudia un fenómeno contemporáneo dentro de su contexto de la vida real, especialmente cuando los límites entre el fenómeno y su contexto no son claramente evidentes" (Yin, 1994: 13). Nos planteamos una serie de preguntas de investigación para abordar este trabajo: ¿cómo se integran las narrativas transmedia a una campaña de publicidad televisiva?; ¿es capaz una pequeña pieza audiovisual como un spot generar fenómeno fandom?; ¿son realmente los últimos anuncios de Lotería de Navidad publicidad transmedia?; ¿cuál es el rol del usuario y cómo contribuye a expandir la historia? Para responder a estos interrogantes, nos marcamos como objetivo general averiguar cómo la narrativa publicitaria de televisión se ha adaptado al contexto transmediático para posteriormente describir y analizar la evolución e incorporación de elementos transmedia en las campañas de publicidad de la Lotería de Navidad. 


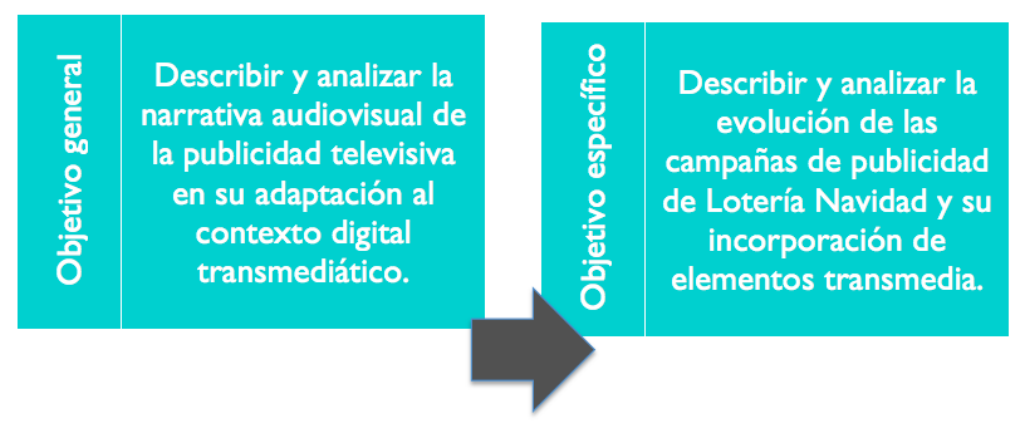

Figura 1. Objetivo general y específico de la investigación. Fuente: elaboración propia.

Los motivos que justifican la elección de este caso es que, como hemos visto, la Lotería de Navidad se lleva celebrando desde 1818, casi dos siglos de antigüedad, y desde 1998 sus spots televisivos adquieren una notoriedad e importancia relevantes. Esta investigación pretende ser una aportación a la comunidad científica sobre las dinámicas publicitarias y estrategias de marketing de la comunicación de Lotería de Navidad. La metodología empleada es eminentemente de naturaleza cualitativa realizando un estudio descriptivo y analítico.

Nos hemos valido de una tabla de análisis narrativo en la que se ha tenido en cuenta una serie de variables cualitativas y cuantitativas que hemos aplicado a las 19 unidades de análisis obtenidas, desde el spot de la campaña de 1998 a la de 2016. El año y la agencia de publicidad responsable nos han valido como variables de identificación. Duración del spot, eslogan, ambientación y escenarios, protagonistas, sonido vocal (vOz en off, vOz in, VOz out y vOz throught), sonido contextual, sonido musical (banda sonora) y tipo de spot se enmarcan dentro de las variables de descripción. En cuanto a las variables de la construcción narrativa transmedia y de experiencia se han tenido en cuenta el storytelling y plot point, la existencia de sitio web asociado (landing page), de otros elementos integrados, como perfiles en redes sociales, apps o acciones de street marketing, entre otros, y la narratividad, identificando los elementos que pertenecen al universo narrativo que expanden la historia y los que conforman un universo no narrativo más orientado a la multiplataforma que a la transmedia que expande la experiencia del usuario pero no el relato.

\section{Resultados}

En 1998 se emite la primera campaña publicitaria en televisión importante sobre el sorteo extraordinario de Navidad. Desde entonces, cada año a mediados de noviembre tiene lugar la emisión de este mítico anuncio que marca el inicio "oficial" de la época navideña. A lo largo de estos años tanto el 
concepto creativo como la estrategia han evolucionado pudiendo establecer cinco etapas bien diferenciadas.

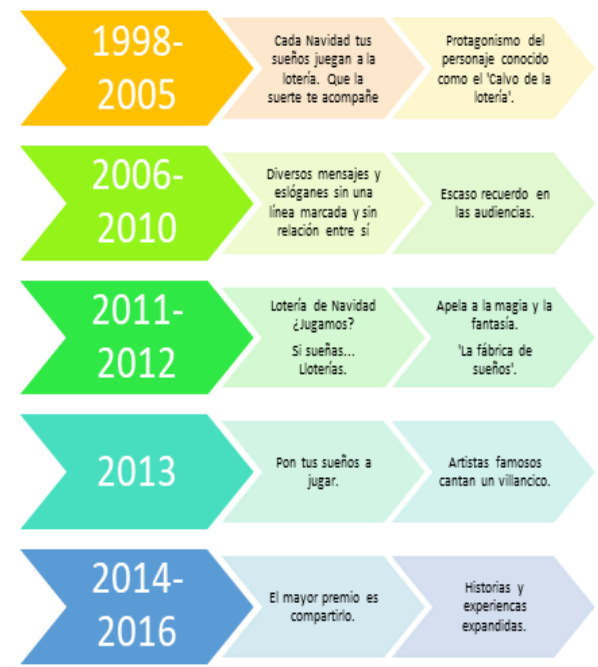

Figura 2. Etapas en las campañas de publicidad de la Lotería de Navidad. Fuente: elaboración propia.

En las siguientes líneas realizamos un exhaustivo análisis de estas etapas en las campañas de Lotería de Navidad mostrando sus diversas características, elementos recurrentes así como novedades. La indagación en el concepto creativo, en la estrategia de difusión y, especialmente, en la experiencia del usuario nos servirán para descubrir las claves que han marcado el camino evolutivo desde un clásico spot de los primeros anuncios a verdaderas películas contadas en escenarios multiplataforma de las últimas campañas.

\subsection{Del 'Calvo de la lotería' a la 'Fábrica de Sueños' (1998-2012)}

Desde el año 1998 al 2005 las campañas de publicidad se limitan a una única acción: el spot en televisión. En su primer anuncio televisivo un personaje de rostro amable soplaba una bola llena de copos de nieve y comenzaba a repartir magia mientras sonaba de fondo la pieza Interior Sudent Cafe de Maurice Jarre, incluida en la banda sonora de la película Doctor Zhivago. Se trata de un vídeo en blanco y negro donde la figura del protagonista se combina con una sucesión de escenas típicamente navideñas que finalizan con una vOz en off masculina que pronuncia la frase "Cada navidad, tus sueños juegan a la lotería" y el eslogan "Que la suerte te acompañe", haciendo un guiño al lema de la conocida saga de la Guerra de las Galaxias. Es precisamente ese entrañable 
personaje interpretado por el actor británico Clive Arrindell quien adquirirá un protagonismo crucial. El conocido popularmente como el 'Calvo de la lotería' protagonizará las campañas sucesivas con un tono y estilo similar, manteniendo el copy y el eslogan, hasta el año 2005. De hecho, este actor firmó una cláusula de exclusividad con Loterías y Apuestas del Estado que le impidió aparecer en cualquier otra producción audiovisual entre 1998 y 2006.

Cambios en la ambientación, en la inclusión de una voz femenina de tono infantil desde 2000 a 2002 y en la inclusión de color desde 2004 serán las variaciones que encontramos en esta primera etapa que lleva la firma de la agencia Publicis España. En 1999 el spot estaba ambientado en el mundo del mar y la minería. En 2000 se eligió la estación de ferrocarril de la población de Canfranc y, junto con los clásicos copos de nieve, se incluye la figura de un hada que recuerda también al mítico personaje ficticio de Campanilla de la obra de teatro y posterior novela Peter Pan. En 2001 estas hadas vuelven a acompañar al protagonista repartiendo magia mientras se repiten las escenas navideñas de familiares y amigos repartiendo regalos. En 2002 encontramos a un niño que junto con el 'Calvo de la lotería' y las hadas encuentran la llave dorada del bombo de la lotería. En el año 2003, y por sexto año consecutivo, el anuncio está protagonizado por Clive Arrindell, consolidado como icono del espíritu navideño, y rodado en Lisboa ambientado en una idealizada posguerra española con más de 150 figurantes. El spot de 2004 se rodó en Madrid, Segovia y el puerto de Estocolmo y, como novedad, el blanco y negro se combina con escenas a color. El año 2005 el spot se desarrolla entre escenas navideñas en las que el entrañable personaje va repartiendo suerte con su mirada y el color sirve nuevamente para ilustrar los sueños de la gente. Por primera vez en este anuncio encontramos sonido contextual del tráfico y ambulancias que se combina con el sonido musical constante.

En 2006 se decide prescindir de la imagen icónica del 'Calvo de la lotería' y cambiar así la dinámica imperante de los últimos anuncios. Ese año, y contra todo pronóstico, ganó el concurso una pequeña agencia española, Ricardo Pérez Asociados, que curiosamente era la responsable del spot de Atún Claro Calvo. El entonces portavoz de Loterías y Apuestas del Estado, César Palazuelos, explicaba a los medios de comunicación que tras llevar ocho años haciendo lo mismo necesitaban cambiar porque "la publicidad exige asumir riesgos" (Marcos, 2006). Desde entonces hasta 2010 encontramos una sucesión de anuncios cuyos conceptos y eslóganes fueron variando sin mantener una relación entre sí. Todo ello derivó en un insuficiente impacto en la sociedad materializado en un escaso o nulo recuerdo. El anuncio de 2006 introdujo una voz en off masculina que empieza preguntándose "¿qué es lo que toca en Navidad?" para repasar algunos de los momentos típicos que se pueden vivir en esa época. También se modificó la música, eligiendo Totò e Alfredo de Ennio Morricone, y el eslogan que pasó a ser "Es lo que toca". 
La campaña del 2007 apostó por unas Navidades que invitan a la solidaridad y a compartir estas fiestas con los allegados. Se muestran diferentes grupos sociales, como los inmigrantes, y culmina con el eslogan "La suerte es de todos". El único elemento en común con la campaña anterior fue el mantenimiento del sonido musical. Al año siguiente un desconocido Lionel Neykov descubierto a través de My Space fue el encargado de repartir suerte a golpe de música indie. Bajo el eslogan "El toque humano de la suerte", el concepto era la idea de que la Navidad lo humaniza todo, apelando al lado más humano de esta época. El anuncio de 2009 mostraba que, en realidad, no hay una única Navidad sino muchas, intentando retratar la multitud de maneras de disfrutar estas fechas. Cuando España estaba ya bien inmersa en una crisis, este spot huye de imágenes nostálgicas e invita al optimismo y la ilusión con un toque de arraigo y tradición, tal y como muestra su eslogan: "Lotería de Navidad: la nuestra". El último anuncio de esta etapa muestra a la diosa Fortuna como representación de la propia Lotería de Navidad. El spot de 2010, rodado en Tarrasa, tiene como estrategia publicitaria el recuerdo sentimental de la infancia a través de la mención de cuentos tradicionales invitando a devolver la ilusión de la niñez y a jugar de nuevo. Solo jugando puedes conseguir que la diosa Fortuna te visite y, por eso, el eslogan insiste: "Lotería de Navidad: ¿jugamos?".

Las campañas de estos años emplean una disparidad de conceptos y eslóganes que no contribuyen al recuerdo. La única característica común de todos estos anuncios fue la presencia constante a lo largo de todo el spot de una voz en off masculina. Sin embargo, todo apunta a que esta voz narradora no ayudó a conectar emocionalmente con el público y, por tanto, fomentar su recuerdo y es por ello que en 2011 y 2012 se vuelve a suprimir, limitando la presencia de ese sonido vocal, femenino en esta ocasión, únicamente al final de la pieza con la reproducción del eslogan. En estos dos años mencionados se apuesta nuevamente por una estupenda selección de sonido musical, que esta vez recayó en la banda sonora de la película de Eduardo Manostijeras, y un mismo concepto basado en un mundo de fantasía donde unos niños hacen realidad los sueños de los jugadores de la Lotería gracias a una mágica Fábrica de Sueños. Esta coherencia también se mantiene en el copy y el eslogan de estos anuncios realizados por la agencia Gray España: "Cada Navidad tus sueños hacen posible la lotería" y "Si sueñas... Loterías". Es en esta etapa donde encontramos una importante novedad y es la creación de un sitio web específico para la campaña (www.lafabricasuenos.com) cuya dirección web se indicaba al final del spot televisivo así como en la cartelería a modo de landing page que permite una extensión del anuncio. 


\subsection{El villancico de la parodia: un punto de inflexión (2013)}

El año 2013 marca un verdadero punto de inflexión en la trayectoria realizada por Loterías y Apuestas del Estado, no solo por el concepto y la estrategia sino, muy especialmente, por la respuesta de los públicos. El spot de este año está dirigido por Pablo Berger, rodado en Pedraza (Segovia) y protagonizado por Montserrat Caballé, Raphael, David Bustamante, Marta Sánchez y Niña Pastori, siendo la primera vez que Lotería de Navidad recurre a la participación de rostros famosos. La idea fue incorporar a la Navidad una canción propia interpretada por las mejores voces de España, que cantan junto al Árbol de la Lotería un villancico, versión del Always On My Mind del mítico Elvis Presley. Se repite la estrategia de lanzar un spot sin historia, valiéndose únicamente de la presencia de estos rostros conocidos.

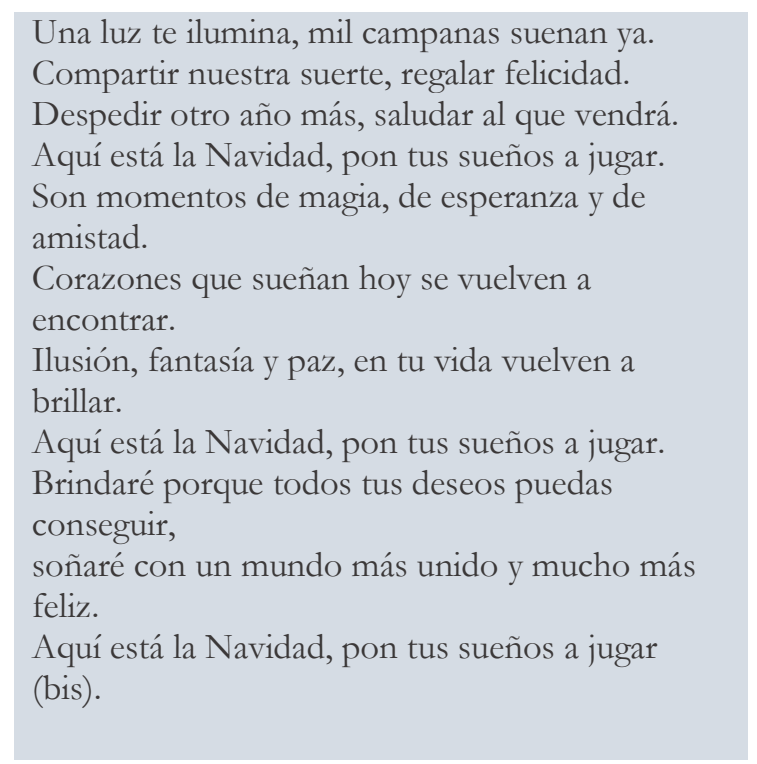

Figura 3. Letra del villancico del spot de Lotería de Navidad de 2013. Fuete: www.quedeletras.com.

Este anuncio, cuyo eslogan "Pon tus sueños a jugar" podría ser el título del citado villancico, alcanza en su versión completa los dos minutos y veinte segundos, superando holgadamente la media de un minuto y seis segundos de las campañas anteriores. Sin embargo, la prolongación del tiempo no corresponde a una complejidad narrativa que así lo requiera sino que se ciñe a la duración media de un single, la del villancico. Es más, en este spot no hay una historia de fondo ni tampoco evoca emociones ni sentimientos con los 
que el público pueda identificarse y empatizar. Una estrategia basada exclusivamente en una canción y la aparición de una serie de famosos resulta deficiente para un anuncio de estas características. El espectador asiste a una actuación de un quinteto cuyo mensaje no cala y donde la presencia del producto, la Lotería de Navidad, está bastante minimizada. La incorporación de una landing page (www.pontussueñosajugar.com), un canal en YouTube (www.youtube.com/user/pontussuenosajugar) y una página en Google+ (www.plus.google.com/u/0/108968882673248738386), que ofrecían material extra como entrevistas al director y los artistas y momentos del making off no alcanzaron apenas notoriedad.

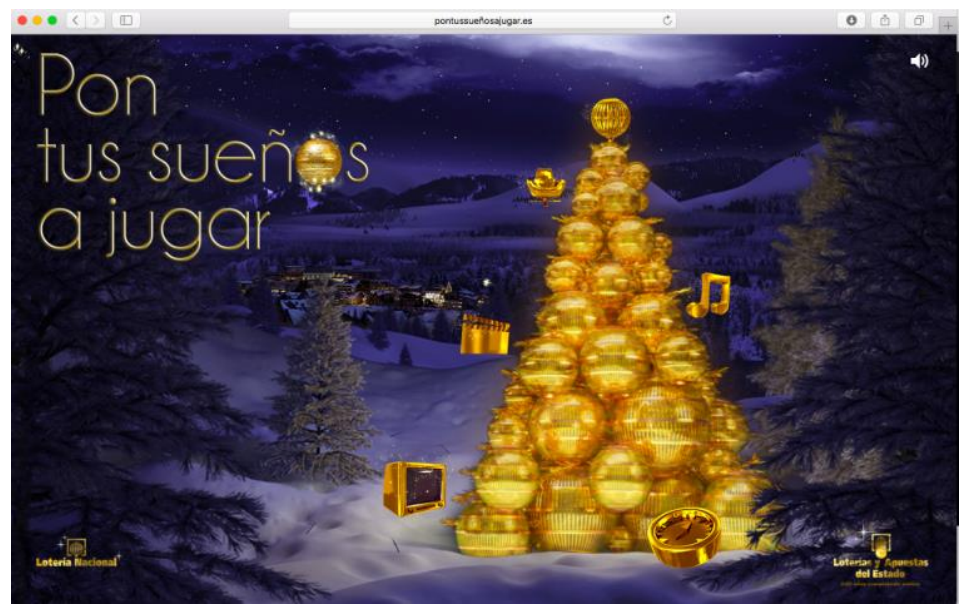

Figura 4. Landing page de la campaña de Lotería de Navidad de 2013. Fuente: www.pontussueñosajugar.com

No obstante, afirmamos con rotundidad que este spot marcó un antes y un después en la relación de los públicos con respecto al esperado anuncio de la Lotería de Navidad. Hasta entonces los espectadores se habían comportado como tal, consumiendo los spots sin mayor implicación. En esta ocasión, el público superó las barreras de consumir y se dedicó a producir. Actuaron como verdaderos prosumidores motivados por una falta de empatía y conexión emocional con la campaña que propició la crítica y la burla, más que a la pieza musical en sí, a la interpretación gestual de los artistas. Por primera vez en la historia de la publicidad de la Lotería de Navidad el público participó activamente expandiendo el contenido a través de la elaboración de parodias, remixes, memes o gifs. 

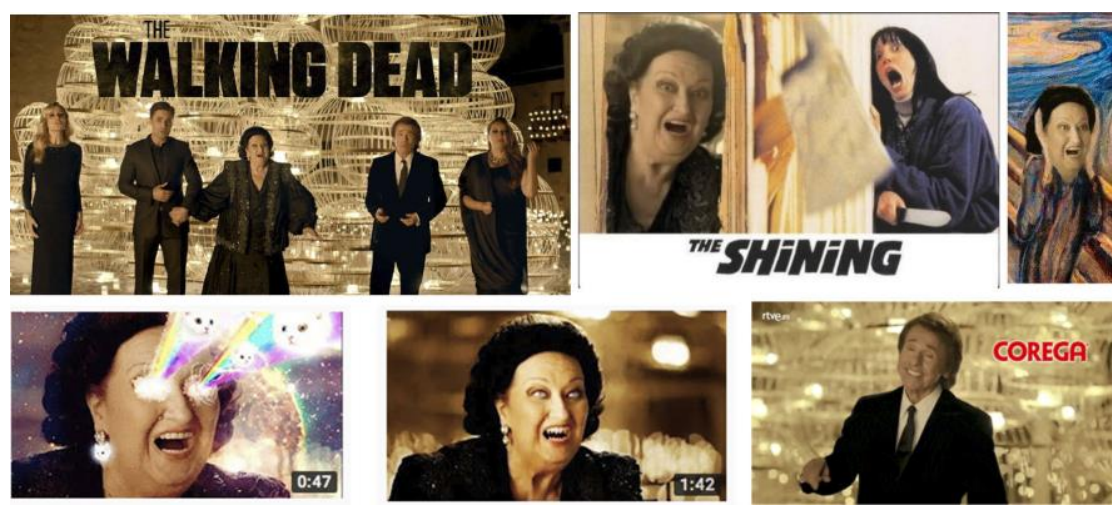

Figura 5. Material elaborado por el público en forma de meme, remix o mashups en torno a la campaña de Lotería de Navidad de 2013. Fuente: elaboración propia a partir de la web.

Desde el momento del estreno, el hashtag \#LoteriaNavidad se convirtió rápidamente en trending topic en Twitter junto a los nombres de algunos de sus protagonistas como \#Raphael. Este fenómeno continuó siendo una fuente imparable de retuits y nuevos contenidos satíricos. Tras esta explosión creativa en tono de burla por parte de los públicos y la proliferación de contenido difundido por redes sociales cabe preguntarse si nos encontramos ante un estrepitoso fracaso o, en cambio, un éxito sin precedentes. Verónica Seguí, la directora de Servicios al Cliente de Tactics Europe, la agencia responsable de la campaña, realizaba las siguientes declaraciones al diario El País: "Queríamos llegar a la gente, crear una comunicación cercana y se ha conseguido, generando visitas, generando viralizaciones y aumentando todas las expectativas" (Ibáñez, 2013).

Está claro que el ingenio de cientos de internautas superó cualquier predicción por parte de la agencia. Surgieron homenajes seriéfilos a series como The Walking Dead o American Horror Story, escenas cinéfilas como en El Resplandor, o Bustamante y Raphael rindiendo tributo a la banda pop estadounidense Backstreet Boys. Todo ello bajo la máxima del sentido del humor. De algún modo el público adoptó un rol muy cercano al propio del fenómeno fandom, generando cross-overs, mashups y remixes en clave de parodia.

\subsection{Transmedia storytelling y experiencia del usuario: las emotivas historias de Manolo, Justino y Carmina (2014-2016)}

A pesar de la viralidad y propagación que adquirió la campaña anterior, y su indudable recordación, Loterías y Apuestas del Estado decide cambiar y 
adoptar definitivamente una estrategia de storytelling de naturaleza emotiva con elementos transmedia y una integración multiplataforma que expanda la historia y la experiencia del usuario. La campaña de 2014 llevó a la pantalla un relato con el que el público se podía identificar y emocionar, una historia de lo más humana dirigida por el cineasta Santiago Zannou. Los protagonistas son Manuel, un vecino en paro de un barrio obrero de una gran ciudad, y Antonio, regente de un bar de la zona que ha repartido el décimo premiado. Un emotivo guion donde confluyen la alegría y felicidad de los agraciados, la generosidad de Antonio por haberle guardado un décimo a su amigo y la emoción de Manuel, mientras se acompaña musicalmente con el tema Glacier de James Vincent McMorrow y que finaliza con una voz en off masculina que pronuncia el eslogan: "El mayor premio es compartirlo".

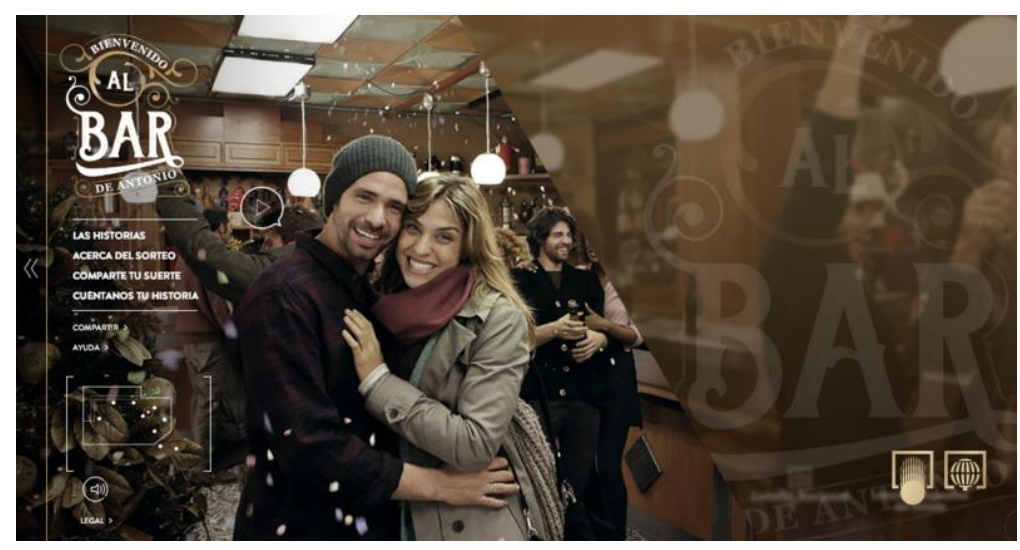

Figura 6. Landing page de la campaña de Lotería de Navidad de 2013. Fuente: www.elbardeantonio.com

Encontramos una emotiva historia como estrategia de storytelling que permite conectar con el receptor y mantener el interés y la atención de las audiencias (Farran, 2014). La duración de la pieza televisiva aumenta considerablemente con respecto a sus predecesoras, alcanzando los cuatro minutos y veinticinco segundos de duración necesarios para contar el relato. Observamos también una integración de plataformas: una landing page (www.elbardeantonio.es) con diversa información sobre el sorteo y en la que el usuario podía tener una experiencia interactiva conociendo nueve historias más entre los agraciados del barrio de Manolo extendiendo la historia central; el desarrollo de una aplicación en Facebook que permitía compartir un décimo llevando la experiencia a la esfera no virtual; y la inclusión de un canal de participación del usuario en el que se le pedía que contara su historia y la compartiera con la comunidad. 

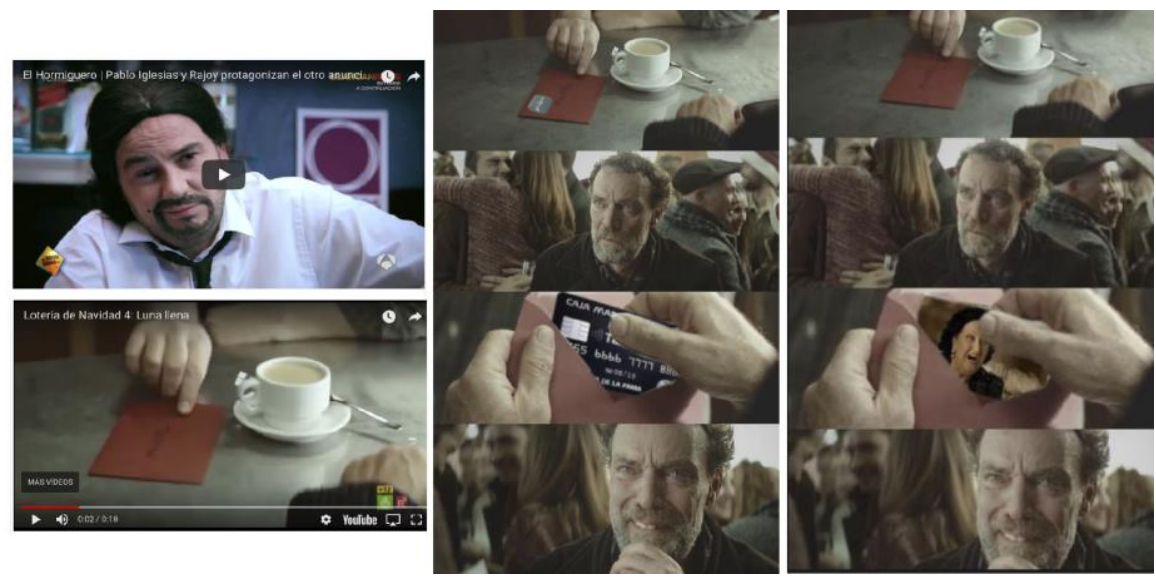

Figura 7. Material elaborado por el público en forma de meme, remix o mashups en torno a la campaña de Lotería de Navidad de 2014. Fuente: elaboración propia a partir de la web.

Aunque la estrategia aquí empleada no es estrictamente transmedia, a través de esas historias paralelas encontramos expansión del relato. Está claro que la propuesta de Leo Burnett, la agencia encargada, era ofrecer nuevas vías de participación del usuario, lo que permitió una rápida propagación por las redes sociales convirtiendo el hashtag \#LoteriaNavidad en trending topic el mismo día del lanzamiento del spot. A pesar de esas posibilidades de colaboración, el usuario ansía tener un papel más activo y no tardaron en proliferar los memes, remixes o mashups no solo de usuarios anónimos sino también de programas de televisión como El Hormiguero de Antena 3 o El Intermedio de La Sexta. Cabe destacar la expansión botton-up generada por el usuario de YouTube Tuti Fernández que realiza una burlesca recreación del desenlace de estos protagonistas pasado un año, en 2015, y otra más, en 2016, superando los dos millones de reproducciones entre ambas y expandiendo esta campaña hasta nuestros días, cuando muchos usuarios le solicitan al ingenioso youtuber que prolongue 'la saga'.

En 2015 la campaña mantiene el mismo concepto, eslogan y estrategia narrando, en esta ocasión, la historia de una fábrica de maniquíes y Justino, su entrañable guardia de seguridad nocturno. Ideado por la agencia de publicidad Leo Burnett, de nuevo cuenta una historia y por primera vez se trata de un vídeo de animación de cuatro minutos de duración con el acompañamiento musical de Nuvole Bianchi de Ludovico Einaudi. La campaña va acompañada por una integración multiplataforma y extensión transmedia: una landing page (www.lafabricademaniquies.es) que actúa de centro organizador del resto de acciones; una página en Facebook de la Fábrica de Maniquíes El Pilar en la que se publica contenido como si la existencia de ese negocio fuera real y en la 
que los públicos pueden interactuar; un perfil en Instagram de Justino donde podemos conocer más profundamente al personaje central: y una acción de street marketing con maniquíes que se sitúan en diversos puntos de Madrid y otras ciudades y que invitan a que el público se fotografíe con ellos.

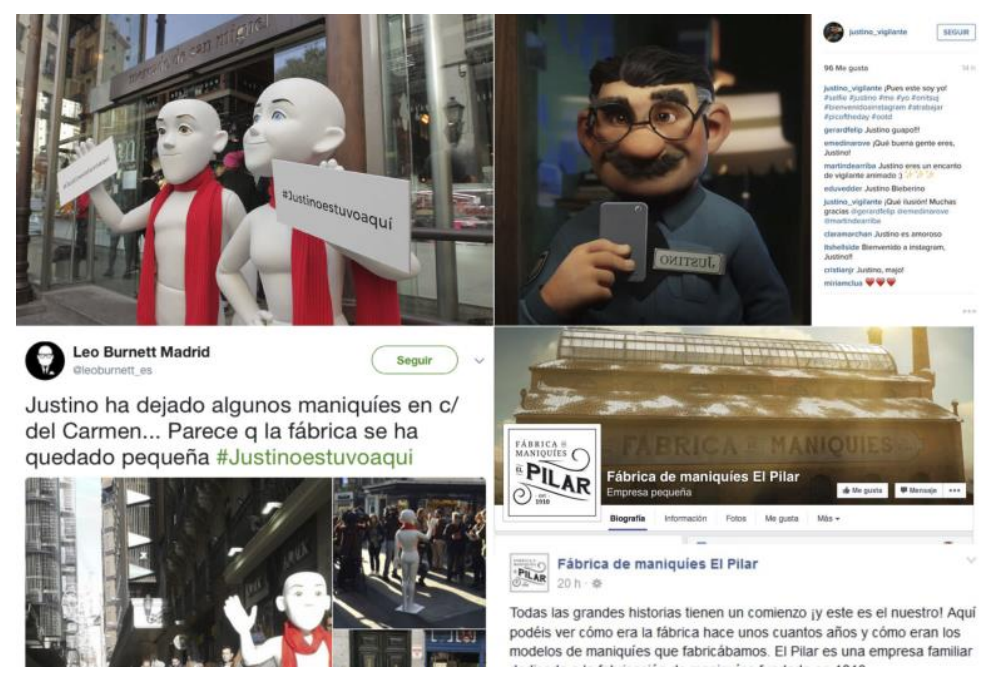

Figura 8. Página de Facebook de la Fábrica de Maniquíes El Pilar, perfil de Instagram de Justino y acción street marketing.

En el caso del anuncio de Justino encontramos una verdadera historia transmedia que utiliza múltiples plataformas con las que el usuario interactúa decidiendo su nivel de inmersión. De forma paralela, se plantean otras acciones que, no perteneciendo al universo narrativo, propagan la historia y aumentan la implicación de las audiencias. El hashtag \#LoteriaNavidad se convirtió en trending topic poco después del lanzamiento del spot oficial y, como era de esperar, las redes volvieron a plagarse de memes y remixes humorísticos en ocasiones con guiños seriéfilos o cinéfilos realizados tanto por usuarios anónimos como por programas de televisión como $A P M$ de TV3 o Vaya Semanita de EITB y cabeceras como la de El Jueves. 

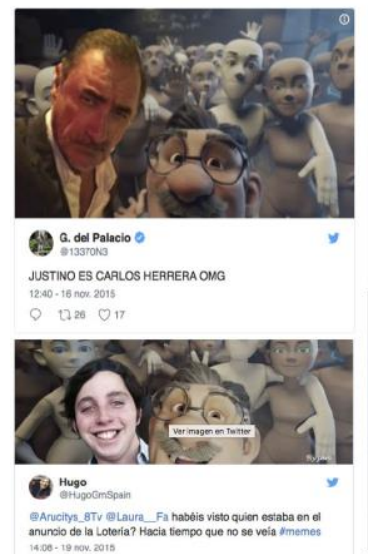

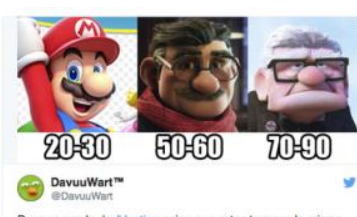

Pues yo con lo de ifJustino opino que estos tres son la misma persona:

$O_{8} \quad$ t] $770 \quad 060$

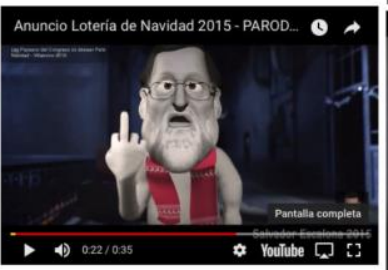

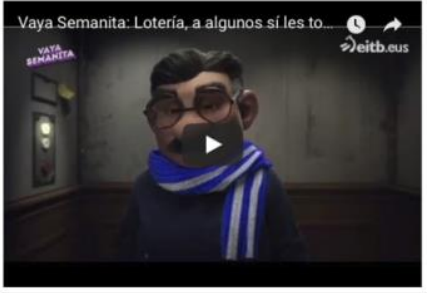

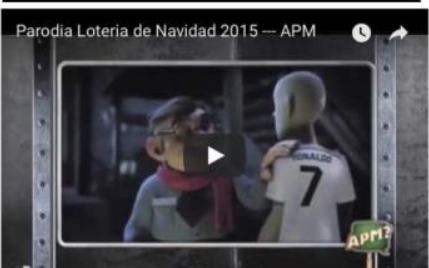

Figura 9. Material elaborado por el público en forma de meme, remix o mashups en torno a la campaña de Lotería de Navidad de 2015. Fuente: elaboración propia a partir de la web.

El año 2016 fue una maestra jubilada, Carmina, la que protagoniza la historia del nuevo anuncio de Lotería de Navidad. En el escenario de una localidad asturiana y con el acompañamiento musical de la obra de Fernando Velázquez, 21 de diciembre, Carmina escucha decir a los niños de San Ildefonso el número del Gordo, que coincide con el de su décimo. De lo que no se da cuenta es que son imágenes de archivo del año anterior y que aún falta un día para el sorteo. Sin embargo, familiares y vecinos del pueblo se vuelcan para mantener la ilusión de esta maestra jubilada.
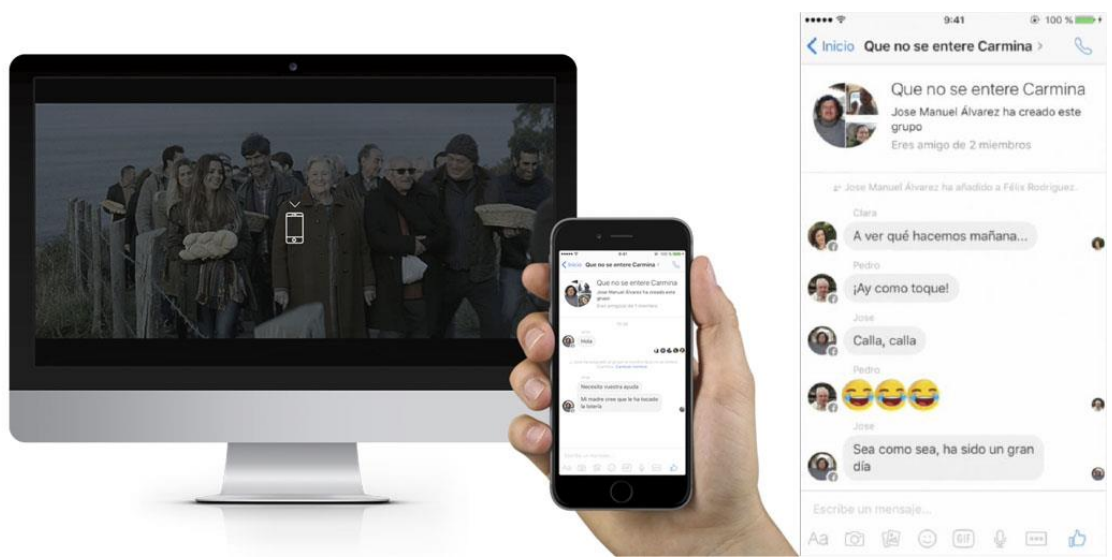

Figura 10. Interfaz del spot interactivo y del grupo de Messenger de Facebook de la campaña de Lotería de Navidad de 2015.

Tanto el concepto como la estrategia mantienen una evidente conexión con 
las campañas anteriores, forjando esa coherencia con el empleo del eslogan "El mayor premio es compartirlo". Nuevamente encontramos a la agencia Leo Burnett detrás de este spot dirigido por Santiago Zannou que vuelve a contar una emotiva historia en cuatro minutos y cincuenta y siete segundos. La transversalidad de la estrategia incluye una integración de plataformas que combina a la perfección storytelling transmedia con experiencia de usuario: una landing page (www.21dediciembre.es) como centro aglutinador de toda la campaña estando fuera del universo narrativo; un grupo de Messenger en Facebook donde el público se integra adoptando el rol de otro vecino del pueblo de Carmina y en cuyo grupo se habla de cómo mantener el 'engaño' a la maestra jubilada, pudiendo el usuario participar e incluso ser apelado por su nombre por otros integrantes del citado grupo; $y$ un spot interactivo en el que se precisa del uso de un ordenador y un Smartphone y en el que el usuario tiene un acceso 'privilegiado' a los mensajes que los vecinos del pueblo se intercambian en un supuesto grupo de Messenger de Facebook y cada vez que un personaje del spot coge su móvil el usuario puede ver a través del suyo lo que está escribiendo. Con esta estrategia transmedia se consigue desplegar la historia a través de múltiples canales pudiendo el púbico elegir su nivel de implicación en la historia logrando además un papel participativo y activo, como en el caso del grupo de Messenger de Facebook, en el que interactúa como un vecino más del pueblo.
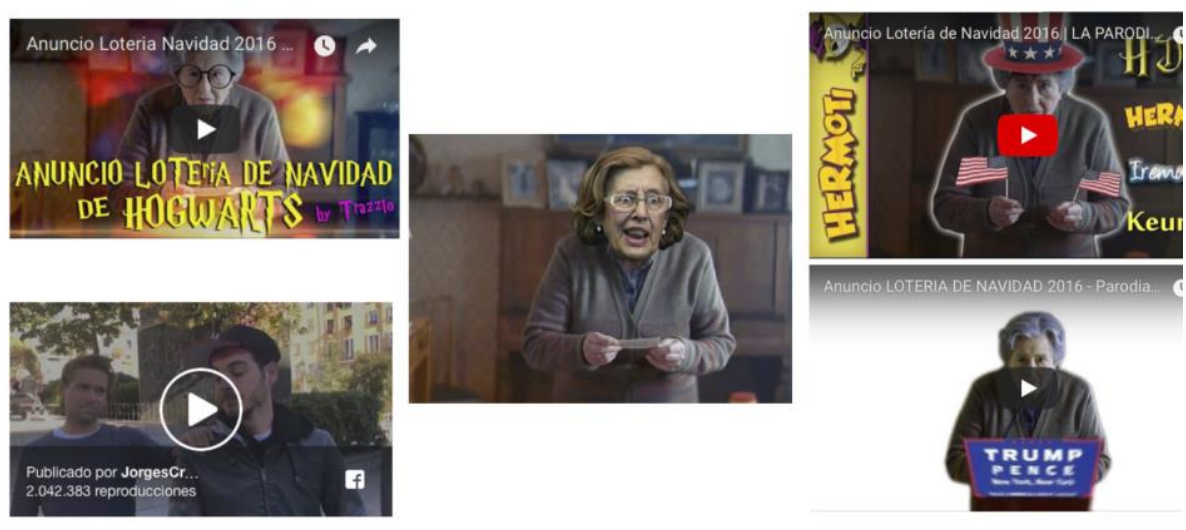

Figura 11. Material elaborado por el público en forma de meme, remix o mashups en torno a la campaña de Lotería de Navidad de 2016. Fuente: elaboración propia a partir de la web.

Pero está claro que el usuario no se satisface con participar en las vías propuestas por las marcas, y es que le encanta crear y reinventar. Así, un año más, asistimos a una multiplicación de parodias en la red, especialmente centradas en esta ocasión en la figura de su protagonista, Carmina. El hashtag \#LoteriaNavidad volvió a alcanzar gran popularidad el mismo día del estreno 
del spot a la vez que los memes y mashups de los públicos inundaban la web y multiplicaban la expansión del anuncio.

De 2014 a 2016 las campañas de publicidad de Lotería de Navidad apuestan por desplegar una conmovedora historia que emocione y conecte con las audiencias. Con el fin de expandir el relato y la propia experiencia del usuario, las campañas se configuran según una perspectiva $360^{\circ}$. Se integran diversas plataformas y acciones de las cuales algunas conforman el universo narrativo, ampliando los canales por donde se cuenta la historia, y otras pertenecen a un universo no narrativo que, si bien no influyen en el relato, sí aumentan la vivencia del usuario. A ello hay que incorporar las iniciativas populares de creación y recreación de las campañas, generando cada vez memes, reximes y mashups en clave de humor que muestran la implicación del usuario, acercándolo al fenómeno fandom, y amplifican la propagación de las campañas.

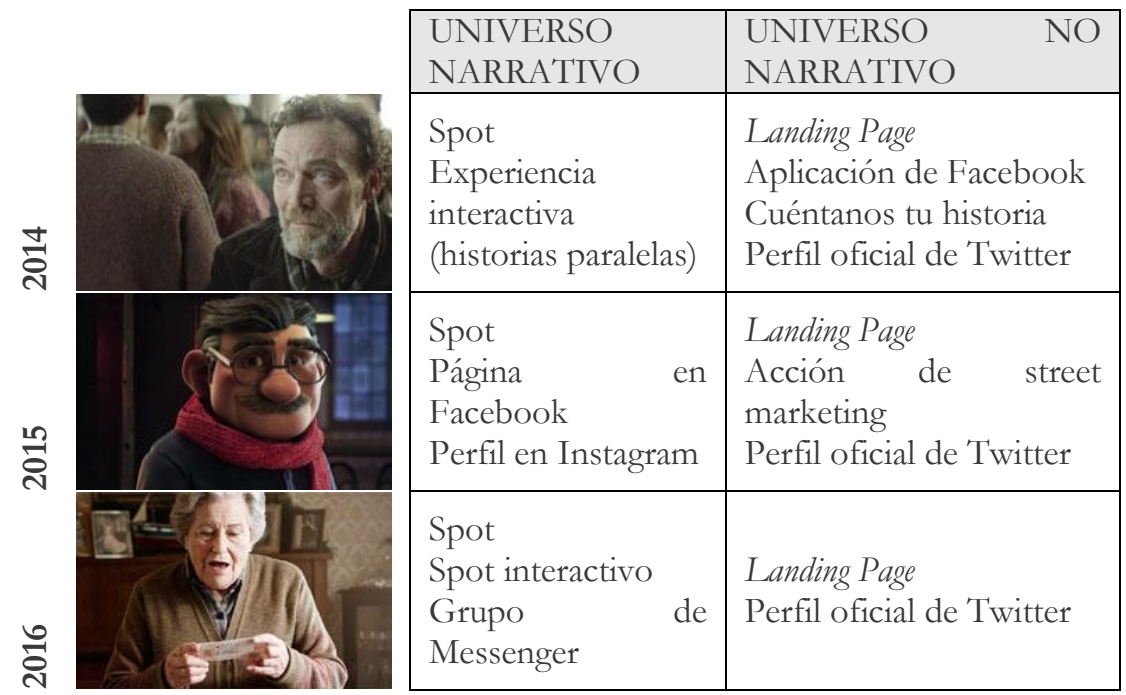

Figura 12. Clasificación de las plataformas en las campañas de Lotería de Navidad de 2014 a 2016. Fuente: elaboración propia.

\section{Discusión y conclusiones}

En la primera etapa, de 1998 a 2012, las campañas se limitan a un spot televisivo de un minuto y seis segundos de media de duración, consistentes en una sucesión de imágenes típicamente navideñas, sonido musical y voz en off. No hay relato ni estructura argumental, con un diverso uso de conceptos y estrategias. En 2013, con el famoso villancico, Lotería de Navidad cambia de estrategia y sin lugar a dudas marcó un antes y un después en la actitud de las audiencias con respecto al spot navideño. Desde entonces, cada año el 
anuncio del Gordo de Navidad se convierte en trending topic el mismo día de su lanzamiento, popularidad y proyección aumentada por las numerosas parodias generadas por los usuarios. En la última etapa observamos una clara evolución de los conceptos y estrategias de las campañas de Lotería de Navidad que van del clásico spot publicitario al storytelling transmedia aumentando considerablemente su duración, con una media de cuatro minutos y veintinueve segundos.

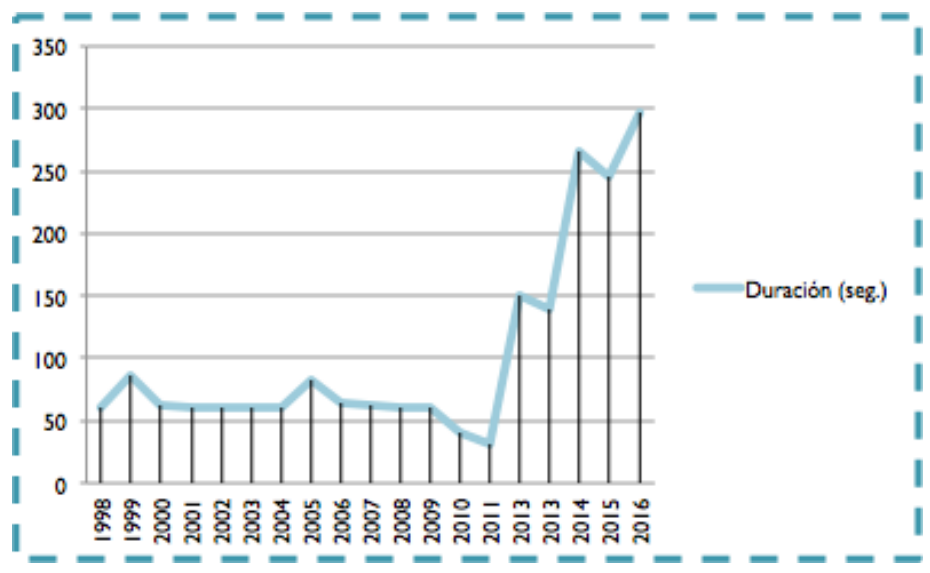

Figura 13. Duración de los spots de las campañas de Lotería de Navidad desde 1998 a 2016.

En la cultura de la narrativa transmedia las historias fluyen a través de múltiples plataformas y medios de comunicación y el usuario adquiere un papel decisivo. Así, en las últimas campañas de Lotería de Navidad se incorporan canales de acción para que los públicos participen activamente. Ahora bien, la experiencia ha demostrado que los usuarios no se sacian con estos canales establecidos y adoptan un rol creador generando sus propios contenidos. Con todo ello, las campañas adquieren una extraordinaria propagación a través de las redes sociales desde el mismo día del lanzamiento oficial del spot y durante toda la época navideña e, incluso, a lo largo de los años (como el caso de Tuti Fernández y sus cortos en YouTube recreando el desenlace de los protagonistas de la campaña de 2014). El usuario vive, revive, reinventa y comparte la historia, aproximándose a un rol típicamente de fan.

\section{Referencias}

Bauman, Z. (2016). Modernidad líquida. Madrid: Fondo de Cultura Económica de España.

Belsunces, A. (2011). Producción, consumo y prácticas culturales en torno a los nuevos 
media en la cultura de la convergencia: el caso de Fringe como narración transmedia. Trabajo Final de Máster, Universitat Oberta de Catalunya. Recuperado de http://openaccess.uoc.edu/webapps/o2/bitstream/10609/8581/1/abelsunce sTFM0611.PDF

Farran Teixidó, E. (2013). Storytelling como herramienta y mejora de la eficacia en publicidad. Análisis de los casos Aquarius y BMW en televisión (1992-2010). Tesis Doctoral, Universdiad Jaume I de Castelló.

Ibáñez, M. (2013, 20 noviembre). El anuncio de la Lotería de Navidad: la parodia llevó al triunfo. En elpais.com. Recuperado de https://elpais.com/sociedad/2013/11/19/actualidad/1384863727_953665.ht $\mathrm{ml}$

Islas, O. (2013). Comprendiendo el tránsito de la blogósfera a la twittósfera. En Islas, O. \& Ricuarte, P. (eds.), Investigar las redes sociales. Comunicación total en la sociedad de la ubicuidad (pp. 63-73). México: Razón y Palabra.

Jenkins, H. \& Ford, S. \& Green, J. (2015). Cultura Transmedia. La creación de contenido y valor en una cultura en red. Barcelona: Gedisa.

Jenkins, H. (2009). The revenge of the origami unicorn: Seven principles of transmedia storytelling. Confessions of an Aca-Fan: The of cial blog of Henry Jenkins. Recuperado de

http://henryjenkins.org/2009/12/the_revenge_of_the_origami_uni.html

Jenkins, H. (2008). Convergene Culture. La cultura de convergencia de los medios de comunicación. Barcelona: Paidós.

Jenkins, H. (2006). Convergence culture: Where old and new media collide. New York: New York University Press.

Jenkins, H. (2003). Transmedia storytelling. Moving characters from books to films to video games can make them stronger and more compelling. Technology Review. Recuperado de http://www.technologyreview.com/biotech/13052/

Lamelo, C. (2016). Televisión social y transmedia. Nuevos paradigmas de producción y consumo televisivo. Barcelona: UOC.

Mandler, J.M. \& Johnson, N.S. (1977). Remembrance of thing parsed: Story structure and recall. Cognitive Psychology, 9, 111-151. 
Marcos, C. (2006, 20 octubre). 'El calvo' de la Lotería muere de éxito. En elmundo.es. Recuperado de

http://www.elmundo.es/elmundo/2006/10/17/comunicacion/1161104127. html

Scolari, C. A. (2013). Narrativa transmedia. Cuando todos los medios cuentan.

Barcelona: Deusto.

Yin, R. K. (1994). Case Study Research: Design and Methods. Thousand Oaks: Sage Publications. 


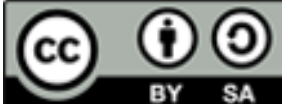

Licencia Creative Commons

Miguel Hernández Communication Journal

mhjournal.org

\section{Cómo citar este texto:}

Noelia García-Estévez (2018) Narrativa transmedia en el spot publicitario. estudio de caso de las campañas de la lotería de Navidad. Miguel Hernández Communication Journal, 9 (1), pp. 49 a 70. Universidad Miguel Hernández, UMH (Elche-Alicante). DOI: http://dx.doi.org/10.21134/mhcj.v0i9.229 